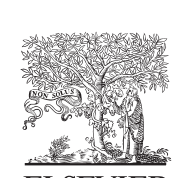

ELSEVIER

\title{
Review
}

\section{An Evidence-Based Guide to Cholesterol-Lowering Guidelines}

\author{
David D. Waters, MD, ${ }^{\mathrm{a}, \mathrm{b}}$ and S. Matthijs Boekholdt, MD, $\mathrm{PhD}^{\mathrm{c}}$ \\ ${ }^{a}$ Division of Cardiology, San Francisco General Hospital, San Francisco, California, USA \\ ${ }^{b}$ Department of Medicine, University of California, San Francisco, California, USA \\ ${ }^{c}$ Department of Cardiology, Academic Medical Center, Amsterdam, The Netherlands
}

\begin{abstract}
Since 2014, guidelines for the management of lipid disorders to reduce cardiovascular (CV) events have been updated in the United States, the United Kingdom, Europe, and Canada. Some of these guidelines are almost entirely evidence-based whereas others are a mix of evidence and expert opinion. Guidelines differ on such simple questions as to whether blood samples should be fasting or nonfasting, and whether low-density lipoprotein cholesterol (LDL-C) or another lipid parameter should be the primary focus of treatment. Different risk assessment tools are recommended by different guidelines. Lifetime risk is highlighted in some guidelines, with the suggestion that earlier treatment will reduce lifetime risk in younger people even when short-term risk is low. Some guidelines have numerical treatment targets that differ according to level of risk, while others eschew targets but recommend statins at high or moderate intensity to reduce LDL-C by $\geq 50 \%$ or $30 \%-50 \%$, respectively. Statins are the backbone of therapy in all guidelines. Ezetimibe produced a $6.4 \%$ relative risk reduction in the only large clinical outcomes trial in which it was tested, and is recommended for high-risk patients with an
\end{abstract}

"It is the beginning of wisdom when you recognize that the best you can do is choose which rules you want to live by, and it's persistent and aggravated imbecility to pretend you can live without any."

-Wallace Stegner, in All the Little Live Things

\section{Guidelines: Quantity and Quality}

A dictionary definition of guideline is a rule or instruction that shows or tells how something should be done. Synonyms include recommendation, instruction, direction, regulation,

Received for publication September 13, 2016. Accepted October 13, 2016.

Corresponding author: Dr David D. Waters, Division of Cardiology, Room 5G1, San Francisco General Hospital, 1001 Potrero Ave, San Francisco, California 94114, USA. Tel.: +1-415-420-6646.

E-mail: David.Waters@ucsf.edu

See page 6 for disclosure information.

\section{RÉSUMÉ}

Depuis 2014, les États-Unis, le Royaume-Uni, l'Europe et le Canada ont procédé à l'actualisation des lignes directrices sur la prise en charge des anomalies lipidiques pour réduire les événements cardiovasculaires (CV). Certaines de ces lignes directrices sont presque entièrement fondées sur les données probantes, tandis que les autres constituent une combinaison de données probantes et d'opinions d'experts. Les lignes directrices diffèrent sur de simples questions quant à savoir si les échantillons de sang devraient être prélevés à jeun ou non à jeun, et si l'objectif principal du traitement devrait porter sur le cholestérol à lipoprotéines de faible densité (cholestérol LDL) ou sur un autre paramètre du bilan lipidique. Les diverses lignes directrices recommandent différents outils d'évaluation des risques. Certaines lignes directrices mettent en relief les risques à vie, et suggèrent qu'un traitement plus précoce les réduira chez les personnes plus jeunes même lorsque les risques à court terme sont faibles. Certaines lignes directrices ont des cibles numériques de traitement qui diffèrent selon le niveau de risque, tandis que d'autres évitent les cibles, mais recommandent un traitement par statines d'intensité élevée ou modérée pour réduire rule, principle, standard, and criterion. Medical guidelines have proliferated over the past 2 decades; as an example, the National Guideline Clearinghouse of the Agency for Healthcare Research lists 417 different guidelines just for hypertension. ${ }^{1}$

Medical guidelines have increasingly become evidencebased, and less dependent on expert opinion. Level of evidence is graded as A when on the basis of multiple randomized clinical trials or meta-analyses, B when on the basis of a single randomized trial or nonrandomized studies, and $\mathrm{C}$ when on the basis of a consensus of opinion of experts, small studies, retrospective studies, and/or registries.

In a survey of American College of Cardiology (ACC)/ American Heart Association (AHA) guidelines from 1984 to 2008 , it was noted that levels of evidence only began to be introduced in $1998 .^{2}$ From 1998 to 2008, of 16 guidelines that reported levels of evidence, comprising a total of 2711 recommendations, only 314 recommendations (11\%) were supported 
inadequate response to statins, despite the high number needed to treat to prevent $1 \mathrm{CV}$ event. Proprotein convertase subtilisin/kexin 9 inhibitors lack outcome data to support their use, but are approved for patients with familial hypercholesterolemia or clinical atherosclerotic CV disease who require additional LDL-C lowering beyond statins. All these new guidelines are aimed at improving the problem of undertreatment of high-risk groups, leading to better outcomes for these patients. by level of evidence A. For acute coronary syndrome, heart failure, and secondary prevention, more than $20 \%$ of recommendations were supported by level of evidence A, compared with $<1 \%$ of recommendations for valvular heart disease.

In the United States, the Medicare Improvements for Patients and Providers Act of 2008 directed the Institute of Medicine to develop standards for clinical practice guidelines. ${ }^{3}$ The report, released in 2011, listed the following standards:

"Clinical practice guidelines are statements that include recommendations intended to optimize patient care that are informed by a systematic review of evidence and an assessment of the benefits and harms of alternative care options.

To be trustworthy, guidelines should

- be based on a systematic review of the existing evidence;

- be developed by a knowledgeable, multidisciplinary panel of experts and representatives from key affected groups;

- consider important patient subgroups and patient preferences, as appropriate;

- be based on an explicit and transparent process that minimizes distortions, biases, and conflicts of interest;

- provide a clear explanation of the logical relationships between alternative care options and health outcomes, and provide ratings of both the quality of evidence and the strength of the recommendations; and

- be reconsidered and revised as appropriate when important new evidence warrants modifications of recommendations."

The report emphasized the importance of transparency in the guideline development process, the need for standards or rules for conflict of interest, and the appropriate level of patient and public input into the guideline development process. The National Guideline Clearinghouse adopted stricter rules as a result of the Institute of Medicine report, and the number of clinical practice guidelines that were accepted in 2014-2015 decreased to 126 from an annual average of 616 over the previous 5 years. ${ }^{4}$

With the foregoing general comments as background, let us turn to examine several issues specific to cholesterollowering guidelines. respectivement le cholestérol LDL de $\geq 50 \%$ ou de $30 \%$ à $50 \%$. Les statines sont le pilier de traitement de toutes les lignes directrices. L'ézétimibe entraînait une réduction du risque relatif de $6,4 \%$ dans la seule grande étude sur les résultats cliniques au cours de laquelle il était testé, et est recommandé chez les patients exposés à un risque élevé qui ont une réponse inadéquate aux statines, en dépit du nombre élevé de sujets à traiter pour empêcher 1 événement CV. Les inhibiteurs de la proprotéine convertase subtilisine/kexine de type 9 manquent de données sur les résultats cliniques pour soutenir leur utilisation, mais sont approuvés chez les patients atteints d'une hypercholestérolémie familiale ou d'une maladie $\mathrm{CV}$ athérosclérotique clinique qui nécessitent un hypocholestérolémiant pour abaisser le cholestérol LDL en plus des statines. Toutes ces nouvelles lignes directrices visent l'amélioration du problème de l'insuffisance de traitement des groupes exposés à un risque élevé afin d'entraîner de meilleurs résultats cliniques chez ces patients.

\section{Same Evidence, Different Conclusion}

Because evidence-based guidelines are on the basis of the same body of evidence, why do they differ? In fact, should not all guidelines be almost identical because they are derived from the same evidence base? The following 2 examples show how different guideline committees can interpret the same evidence and arrive at opposite recommendations.

It is generally agreed that fasting and nonfasting blood samples yield similar measurements for high-density lipoprotein (HDL) cholesterol, and that nonfasting samples are slightly higher for total and LDL-C, and up to $25 \mathrm{mg} / \mathrm{dL}$ higher for triglycerides. ${ }^{5}$ The 2011 European Society of Cardiology (ESC)/European Atherosclerosis Society (EAS) guidelines recommended that blood sampling should be performed after a 12-hour fast. ${ }^{6}$ The British National Clinical Guideline Center (National Institute for Health and Care and Excellence [NICE]) guidelines state that a fasting sample is not needed, ${ }^{7}$ and the ACC/AHA guidelines state that a fasting sample is preferred but not mandatory, ${ }^{8}$ whereas the new Canadian guidelines recommended a nonfasting lipid determination "as a suitable alternative" to fasting levels." The 2016 ESC/EAS guidelines agree that a nonfasting sample is acceptable for risk assessment, but recommend a fasting sample for follow-up of patients with severe hyperlipidemia or hypertriglyceridemia. ${ }^{10}$

LDL-C has traditionally been the primary measurement upon which treatment decisions are based, and is a strong, independent predictor of future cardiovascular (CV) events. However, it is now widely accepted that non-HDL cholesterol and apolipoprotein (apo) B are somewhat superior predictors of events. ${ }^{11}$ Non-HDL cholesterol does not require an additional measurement as does apo $\mathrm{B}$, and does not require a fasting sample. Have guideline writers recognized the superiority of non-HDL cholesterol? The NICE guidelines do recommend that non-HDL cholesterol be used during follow-up to assess treatment, ${ }^{7}$ but the ESC/EAS guidelines still recommend LDL-C and total cholesterol as the primary target of therapy, ${ }^{6,10}$ whereas the ACC/AHA guidelines recommend either LDL-C or non-HDL cholesterol, ${ }^{8}$ and the Canadian guidelines recommend LDL-C as the primary target, with non-HDL cholesterol and apo B as alternate targets. 
Guideline committees probably all agree on the evidence, but small variations in the wording of their recommendations lead to wide variations in practice for seemingly simple issues like fasting or nonfasting blood samples, and the lipid parameter to use for risk assessment and treatment decisions. Some of the other differences among the guidelines are listed in Table 1.

\section{Risk Assessment}

A key principle of all cholesterol guidelines is that the decision to treat should be on the basis of the level of CV risk, not the level of cholesterol. It is far more cost-effective to treat a very high-risk patient with a low-density lipoprotein cholesterol (LDL-C) level of $2.6 \mathrm{mmol} / \mathrm{L}(100 \mathrm{mg} / \mathrm{dL})$ than to treat a very low-risk patient with an LDL-C level of $4 \mathrm{mmol} / \mathrm{L}$ $(155 \mathrm{mg} / \mathrm{dL})$.

Certain features are desirable in a risk assessment tool. Ideally, it should calculate risk for the important clinical CV end points: $\mathrm{CV}$ death, myocardial infarction (MI), and stroke. In addition, it should be derived from a population similar to the population in which it will be used. A risk calculator based on a population in Framingham might not be accurate for a Bengali resident of Vancouver or an Inuit in Yellowknife. Ideally, a risk calculator should be convenient or it will not be used at all.

In Table 2, 4 of the most widely used risk assessment tools are compared. The Framingham Risk Score (FRS) has been calibrated in many different populations and has been shown to be accurate in cohorts from the United States, Australia, and New Zealand, whereas it overestimates risk in European cohorts. ${ }^{14}$ The Canadian guidelines have used the FRS augmented by a positive family history of CV disease (CVD; younger than 55 years in first-degree male relatives and

Table 1. Differences among major guidelines

\begin{tabular}{|c|c|c|c|}
\hline Organization & Risk assessment & $\begin{array}{l}\text { Recommended } \\
\text { treatment }\end{array}$ & $\begin{array}{c}\text { Ezetimibe or PCSK9 } \\
\text { inhibitors }\end{array}$ \\
\hline$\overline{\mathrm{ACC} / \mathrm{AHA}^{8}}$ & $\begin{array}{l}\text { Pooled cohort } \\
\text { equation }\end{array}$ & $\begin{array}{l}\text { High- or moderate- } \\
\text { intensity statin to } \\
\text { lower LDL-C by } \\
\geq 50 \% \text { or } 30 \% \text { - } \\
50 \% \text {, respectively }\end{array}$ & $\begin{array}{l}\text { No outcome data } \\
\text { available at the } \\
\text { time of } \\
\text { publication }\end{array}$ \\
\hline $\mathrm{NICE}^{7}$ & QRISK2 & $\begin{array}{l}\text { Atorvastatin } 20 \mathrm{mg} \\
\text { for primary and } \\
80 \mathrm{mg} \text { for } \\
\text { secondary } \\
\text { prevention }\end{array}$ & $\begin{array}{l}\text { No outcome data } \\
\text { available at the } \\
\text { time of } \\
\text { publication }\end{array}$ \\
\hline $\mathrm{ESC}^{\mathrm{E}} \mathrm{ESS}^{10}$ & SCORE charts & $\begin{array}{l}\text { LDL-C targets for } \\
\text { level of risk and } \\
50 \% \text { LDL-C } \\
\text { reduction for most } \\
\text { high- or very high- } \\
\text { risk patients }\end{array}$ & $\begin{array}{l}\text { Recommended as } \\
\text { second-line } \mathrm{Rx}\end{array}$ \\
\hline $\mathrm{CCS}^{9}$ & $\begin{array}{l}\text { Modified } \\
\text { Framingham }\end{array}$ & $\begin{array}{l}\text { LDL-C }<2 \mathrm{mmol} / \mathrm{L} \\
\text { or }>50 \% \mathrm{LDL}-\mathrm{C} \\
\text { reduction }\end{array}$ & $\begin{array}{r}\text { Recommended as } \\
\text { second-line } \mathrm{Rx}\end{array}$ \\
\hline
\end{tabular}

ACC/AHA, American College of Cardiology/American Heart Association; CCS, Canadian Cardiovascular Society; ESC/EAS, European Society of Cardiology/European Atherosclerosis Society; LDL-C, low-density lipoprotein cholesterol; NICE, National Institute for Health and Care and Excellence; PCSK9, Proprotein convertase subtilisin/kexin 9; Rx, prescription; SCORE, Systematic Coronary Risk Evaluation. younger than 65 years in female relatives) since 2006, although subsequent evidence from a large European cohort showed that combining family history with FRS did not improve classification of individuals into clinically relevant risk categories. ${ }^{15}$

Although previous American guidelines had recommended the FRS to assess risk, the ACC/AHA guidelines rejected the FRS because it was derived from an exclusively white population and because the outcome did not include stroke. ${ }^{16}$ Instead the committee developed the Pooled Cohort Equations from several large geographically and racially diverse modern National Heart, Lung, and Blood Institute-sponsored cohort studies, combined with data from the Framingham original and Offspring Study cohorts. These equations provide sex- and race-specific estimates of 10-year and lifetime risk of $\mathrm{CV}$ death, MI, and stroke for African-American and white men and women aged $40-79$ years. ${ }^{16}$

In Europe, Systematic Coronary Risk Evaluation (SCORE) charts are the standard risk assessment tool. They combine sex, age, total cholesterol, systolic blood pressure, and smoking status to provide a 10-year risk estimate for CV death. Versions are available for high- and low-risk European countries and separate charts have been developed for subjects with diabetes. A limitation of SCORE is the absence of nonfatal CV events, specifically MI and stroke, in the end point; however, CV deaths include those from hypertensive heart disease, heart failure, and stroke, as well as coronary disease.

QRISK2 is the risk assessment tool recommended by the NICE guidelines. It aggregates patient-level data from all 1243 practices in England and is updated annually. Various ethnicities in addition to white (Indian, Pakistani, Bangladeshi, other Asian, black Caribbean, black African, and Chinese) can be entered, as can medical conditions associated with increased CV risk such as atrial fibrillation, chronic kidney disease, and rheumatoid arthritis. The original version was on the basis of 2.3 million patients aged 35-74 years with $140,000 \mathrm{CV}$ events, and showed superior discrimination and calibration in British patients compared with the modified FRS. ${ }^{17}$ QRISK2 includes the Townsend index, a marker of social deprivation, which is derived from the patient's postal code. QRISK2 loses some of its accuracy when the postal code is omitted; but otherwise can be used in non-British patients.

\section{Lifetime Risk}

A limitation of most risk assessment tools has been that their horizon is 10 years. This biases the decision to initiate treatment toward older individuals, and to a lesser extent, toward men. The 10-year risk for a 45 -year old person is low, even with multiple risk factors, whereas it is much higher for a 75-year old person with fewer or no risk factors, because risk increases with age. The ACC/AHA guidelines recommend consideration of statin therapy for individuals age 40-75 years with an LDL-C of $1.8-5.0 \mathrm{mmol} / \mathrm{L}(70-189 \mathrm{mg} / \mathrm{dL})$ if 10 -year risk is $\geq 7.5 \%$, a level reached by a 65 -year-old man and a 71 year-old woman with optimal risk factors.

However, a 45-year-old woman with an LDL-C of 4.8 $\mathrm{mmol} / \mathrm{L}(185 \mathrm{mg} / \mathrm{dL})$ would not be eligible for treatment because her 10-year risk is very low. However, her lifetime risk is high, and accumulating evidence indicates that 
Table 2. A comparison of risk assessment tools

\begin{tabular}{|c|c|c|c|c|}
\hline Tool & End points included & Computer application & Advantages & Disadvantages \\
\hline$\overline{\text { Framingham Risk Score }}$ & CV death, MI, (stroke, PAD, HF)* & CCS app ${ }^{\dagger}$ & Well studied cohort & Homogeneous white population \\
\hline ACC/AHA & CV death, MI, stroke & Yes $^{\ddagger}$ & $\begin{array}{r}\text { Includes African American } \\
\text { individuals; lifetime risk }\end{array}$ & $\begin{array}{l}\text { Accuracy questioned; limited } \\
\text { ethnic representation }\end{array}$ \\
\hline SCORE & CV death & Registration required $^{\S}$ & $\begin{array}{l}\text { Calibrated for different European } \\
\text { regions }\end{array}$ & Limited end point \\
\hline QRISK2 & MI, stroke & Yes" & $\begin{array}{l}\text { Updated yearly; multiple ethnic } \\
\text { groups; countrywide database }\end{array}$ & $\begin{array}{l}\text { Based on United Kingdom data } \\
\text { only }\end{array}$ \\
\hline
\end{tabular}

ACC/AHA, American College of Cardiology/American Heart Association; CV, cardiovascular; HF, heart failure; MI, myocardial infarction; PAD, peripheral arterial disease; SCORE, Systematic Coronary Risk Evaluation.

${ }^{*}$ The earlier version of the Framingham Risk Score includes CV death and MI only, ${ }^{12}$ while later versions also include stroke, peripheral artery disease and heart failure. ${ }^{13}$

${ }^{\dagger}$ www.ccs.ca/en/resources/mobile-apps.

$\ddagger$ www.cvriskcalculator.com/.

$\S$ www.heartscore.org/.

"www.qrisk.org/.

atherosclerosis develops gradually from a young age, and that correction of hypercholesterolemia at an earlier age would more effectively reduce lifetime risk, compared with withholding treatment until later in life when risk is increased. Genetic studies indicate that subjects with LDL-C-increasing mutations, and thus lifelong hypercholesterolemia, are at greater risk for $\mathrm{CV}$ events than are subjects without genetic mutations but with similar LDL-C levels, although risk is very high in both groups. ${ }^{18,19}$

A limitation of earlier initiation of preventive treatment for people at low short-term, but high long-term risk is the low compliance levels that have been documented with statins. Discontinuing a statin in the first year or two of treatment is likely to have little effect in a younger individual with a high lifetime risk.

\section{LDL-C Treatment Targets}

One of the differences among guidelines, and perhaps the main point of contention, is that some guidelines have specific numeric treatment targets whereas others recommend differing intensities of statin treatment. For example, the new European guidelines recommend a target LDL-C level of 2.6 $\mathrm{mmol} / \mathrm{L}(100 \mathrm{mg} / \mathrm{dL})$ for high-risk patients, with $1.8 \mathrm{mmol} / \mathrm{L}$ $(70 \mathrm{mg} / \mathrm{dL})$ as a target for very high-risk patients. ${ }^{10}$ They also recommend a $50 \%$ reduction in LDL-C if baseline LDL-C is between 2.6 and $5.2 \mathrm{mmol} / \mathrm{L}$ for high-risk patients or between 1.8 and $3.5 \mathrm{mmol} / \mathrm{L}$ for very high-risk patients. In contrast, the ACC/AHA guidelines recommend high- or moderateintensity statin therapy for all patient groups, defined as treatment expected to reduce LDL-C by $\geq 50 \%$ or $30 \%$ $50 \%$, respectively. ${ }^{8}$ The Canadian guidelines include a numeric target as well as a percentage reduction; specifically, an LDL-C consistently $<2.0 \mathrm{mmol} / \mathrm{L}$ or a $>50 \%$ reduction of LDL-C.? The NICE guidelines recommend a specific dose of a specific statin, atorvastatin $20 \mathrm{mg}$ for primary and $80 \mathrm{mg}$ for secondary prevention, with a non-HDL cholesterol reduction of $>40 \%$ as the target for secondary prevention.

The clinical trial data indicate that for each $\mathrm{mmol} / \mathrm{L}(38.6$ $\mathrm{mg} / \mathrm{dL}$ ) reduction in LDL-C, CV events are reduced by $22 \%$ (95\% confidence interval [CI], 20\%-24\%) across a broad range of baseline LDL-C levels. ${ }^{20}$ The data do not support the choice of a specific target such as $2.6 \mathrm{mmol} / \mathrm{L}$, as opposed to
2.0 or $3.0 \mathrm{mmol} / \mathrm{L}$, or a $50 \%$ LDL-C reduction, as opposed to a $45 \%$ or $55 \%$ reduction. Benefit is continuous with increasing amounts of LDL-C reduction, with no specific threshold value below which benefit ceases to accrue. Furthermore, a recent study indicates that although percentage of LDL-C reduction adds incremental prognostic value over statin dose and attained LDL-C level, attained LDL-C level does not provide additional prognostic value over statin dose and percentage of LDL-C reduction. ${ }^{21}$ If the target for a very high-risk patient is $1.8 \mathrm{mmol} / \mathrm{L}$, a patient with an LDL-C level of $1.75 \mathrm{mmol} / \mathrm{L}$ would not qualify for treatment, whereas one with an LDL-C of $1.85 \mathrm{mmol} / \mathrm{L}$ could achieve goal with a trivial reduction in LDL-C. ${ }^{22}$ Despite these considerations, target LDL-C levels are stubbornly entrenched in some lipid guidelines.

Again, different guideline committees have interpreted the available evidence differently, and came to different recommendations. ACC/AHA focused on level A evidence from randomized trials, and thus recommended drugs and doses tested in these trials. ESC and Canadian guideline writers used a broader body of evidence, and included observational data that showed that people reaching lower LDL-C levels have lower CVD risk and therefore did make recommendations along these lines.

The stark contrast between the European guidelines with numerical targets and the ACC/AHA statin intensity-based guidelines has softened recently. The 2016 ACC expert consensus decision pathway, while not carrying the weight of sanctioned guidelines, includes numerical LDL-C targets as a guide to physicians and patients. ${ }^{23}$ The new ESC guidelines concede that "Lowering LDL-C beyond the goals that were set in the previous EAS/ESC guidelines is associated with fewer CV events. Therefore, it seems appropriate to reduce LDL-C as low as possible, at least in patients at very high CV risk." ${ }^{10}$ The ESC guidelines also include the recommendation for $50 \%$ LDL-C reductions for some categories of patients. In most cases, a $50 \%$ LDL-C reduction is the equivalent of a high-intensity statin.

The response to a specific dose of a statin is much more variable than physicians realize, as shown in Figure $1 .{ }^{24}$ Part of this variability is due to incomplete adherence to treatment; however, these data are derived from a clinical trial, where compliance is expected to be better than in clinical practice. Is 


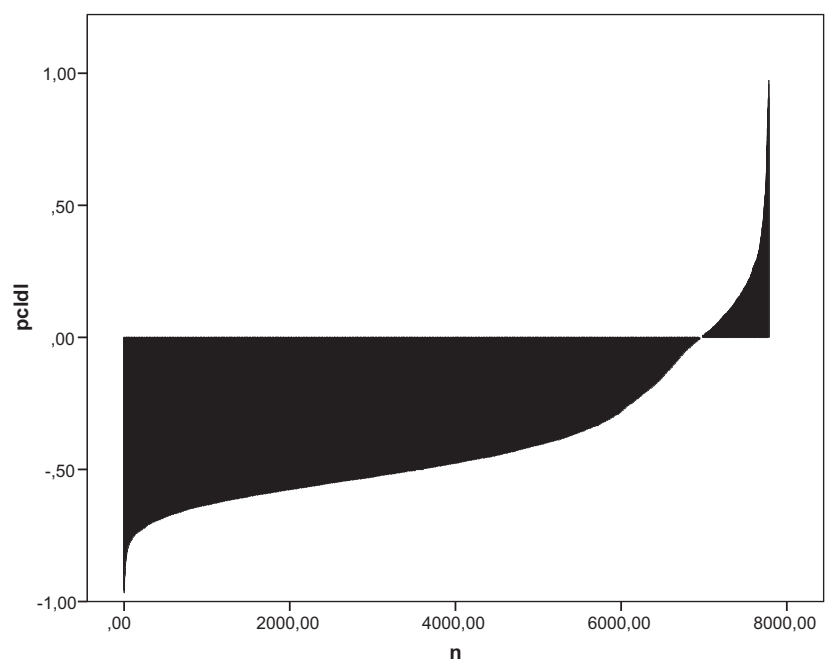

Figure 1. Waterfall plot showing the difference in low-density lipoprotein (LDL) cholesterol between baseline and 1 year for 8000 patients taking rosuvastatin $20 \mathrm{mg} / \mathrm{d}$ in the Justification for the Use of Statins in Prevention: An Intervention Trial Evaluating Rosuvastatin (JUPITER) trial. The patients are lined up with the best responders on the left and the worst on the right. Modified from Boekholdt et al. ${ }^{24}$ with permission from Elsevier.

the response to treatment related to clinical outcome? Among patients randomized to placebo or rosuvastatin $20 \mathrm{mg} / \mathrm{d}$, incidence rates in the Justification for the Use of Statins in Prevention: An Intervention Trial Evaluating Rosuvastatin (JUPITER) trial for the primary end point were 11.2, 9.2, 6.7 , and 4.8 per 1000 person-years for those in the placebo, no LDL-C reduction, LDL-C reduction $<50 \%$, and LDL-C reduction $\geq 50 \%$ groups, respectively. ${ }^{25}$ Thus, it is important to measure the response to a statin, and to consider more aggressive therapy, either with drugs or diet or improved compliance, in poor responders.

\section{Absolute Risk Reduction}

The calculation of absolute risk reduction (ARR) for an individual provides a precise and personalized assessment of benefit. $^{26-28}$ The calculation depends upon the following components; first, a $1 \mathrm{mmol} / \mathrm{L}(38.6 \mathrm{mg} / \mathrm{dL})$ reduction in LDL-C reduces CV events by $22 \%$, according to the metaanalysis of the Cholesterol Treatment Trialists' Collaboration. $^{20}$ Statin therapy reduces LDL-C by a percentage of baseline LDL-C. Thus, a 50\% reduction in LDL-C produces a larger numerical reduction in LDL-C when the baseline LDL-C is high, and thus a larger reduction in CV events. To calculate ARR, one needs to know baseline LDL-C level, baseline risk, and amount of LDL-C reduction. Number needed to treat (NNT) is equal to 100 divided by ARR. It is generally accepted that an NNT of $<50$ is acceptable to physicians, and an NNT $<30$ is acceptable to patients. ${ }^{29}$

Figure 2 shows the NNT that result from 20\% and 50\% LDL-C-lowering for 5-year CVD risks of 5\%, 10\%, and $20 \%$, at baseline LDL-C levels from $190 \mathrm{mg} / \mathrm{dL}$ (5 mmol/L) to $70 \mathrm{mg} / \mathrm{dL}(1.8 \mathrm{mmol} / \mathrm{L})$. For a $20 \% \mathrm{LDL}-\mathrm{C}$ reduction, the NNT is favourable only for very high-risk patients $(20 \%$ 5 -year risk) or for high-risk patients (10\% 5-year risk) when
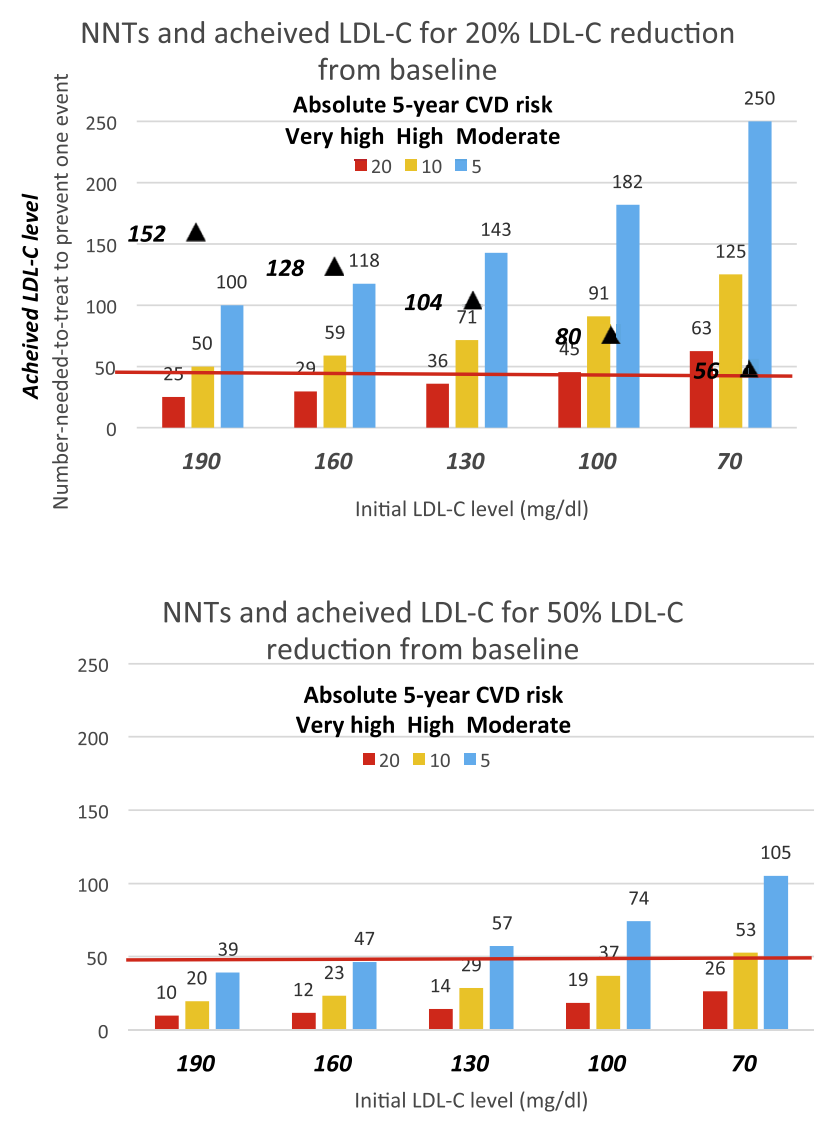

Figure 2. Number needed to treat (NNT) for 5 years to prevent one cardiovascular event assuming a $20 \%$ reduction in low-density lipoprotein cholesterol (LDL-C; top) and a 50\% reduction in LDL-C (bottom). The horizontal axis shows baseline LDL-C levels ranging from 190 to $70 \mathrm{mg} / \mathrm{dL}$ ( 5.0 to $1.8 \mathrm{mmol} / \mathrm{L}$ ). Red, yellow, and blue bars depict very high, high, and moderate 5-year cardiovascular risk, respectively. The black triangles represent achieved LDL-C levels and the red horizontal line a NNT of 50 , often considered to be the threshold below which treatment is worthwhile. Note that the NNT for treatment is favourable for many more subgroups with a $50 \%$ compared with a $20 \%$ LDL-C reduction. CVD, cardiovascular disease. Modified from Robinson ${ }^{27}$ with permission from Oxford University Press.

LDL-C is very high. A $50 \%$ LDL-C reduction produces a favourable NNT for all groups except moderate risk $(5 \% 5-$ year risk) patients with a baseline LDL-C level of $\leq 130 \mathrm{mg} /$ $\mathrm{dL}(3.4 \mathrm{mmol} / \mathrm{L})$.

A computer application that calculates ARR and NNT on the basis of individual patient values has not yet been developed. Such an application would go beyond risk assessment to provide a measure of the benefit of treatment. NNT should be balanced against number needed to harm, but for most patients treated with statins, adverse effects that persist after treatment discontinuation are very rare. The balance between benefit and risk with statins is discussed in detail in a recent review by Collins et al. ${ }^{30}$

\section{Nonstatin LDL-C-Lowering Options}

Fibrates and niacin have not reduced CV events in clinical trials in which patients were treated with statins, and thus are 
not recommended by guidelines as add-on therapy. ${ }^{6-9}$ The only LDL-C-lowering drug that has been shown to reduce CV events in statin-treated patients is ezetimibe. In the Improved Reduction of Outcomes: Vytorin Efficacy International Trial (IMPROVE-IT), ${ }^{31}$ 18,144 post-acute coronary syndrome patients were randomized to simvastatin $40 \mathrm{mg} / \mathrm{d}$ alone or with ezetimibe $10 \mathrm{mg} / \mathrm{d}$. The primary end point was a composite of CV death, MI, unstable angina requiring hospitalization, coronary revascularization, and stroke, and patients were followed for a median of 6 years. The mean LDL-C level in the group that received ezetimibe was lower, 1.4 compared with $1.8 \mathrm{mmol} / \mathrm{L}(53.7$ vs $69.5 \mathrm{mg} / \mathrm{dL})$. The primary end point at 7 years was $32.7 \%$ in the combination therapy group and $34.7 \%$ in the simvastatin-alone group, a $6.4 \%$ relative risk reduction $(P=0.016)$.

The NNT to prevent $1 \mathrm{CV}$ event in IMPROVE-IT was 50 for 7 years of treatment, or 350 for 1 year of treatment. The application to approve the simvastatin/ezetimibe combination for the reduction of CV events was rejected by the US Food and Drug Administration in the United States, after a 10 to 5 vote against approval by an advisory panel, but was approved by the European Medicines Agency. Subgroup analyses of IMPROVE-IT showed a significant clinical benefit in the 4933 patients with diabetes (hazard ratio [HR], 0.86; 95\% CI, 0.78-0.94; $P=0.001)$, and in the 2797 patients aged 75 years or older (HR $0.80 ; 95 \% \mathrm{CI}, 0.70-0.90 ; P=0.0003$ ), but not in nondiabetic patients (HR, 0.98; 95\% CI, $0.91-1.04 ; P=0.49)$ or patients younger than 75 years of age (HR, 0.97; 95\% CI, 0.91-1.03; $P=0.34$ ). ${ }^{32}$

How have these findings been interpreted by recent guidelines, and how should they be integrated into clinical practice? The European and Canadian guidelines recommend that consideration be given to the combination of ezetimibe with a statin in selected patients who do not attain treatment targets with statins alone. ${ }^{9,10}$ The ACC Task Force on Clinical Expert Consensus Documents recently published an "expert consensus decision pathway on the role of nonstatin therapies for LDL-C-lowering." ${ }^{23}$ While emphasizing that the Task Force did not use the rigourous methodology used for guideline development, they recommended that ezetimibe be considered for patients with an inadequate response to statin therapy.

Proprotein convertase subtilisin/kexin 9 (PCSK9) inhibitors profoundly reduce LDL-C and in preliminary studies appear to reduce $\mathrm{CV}$ events by approximately $50 \%$. ${ }^{33}$ Large clinical trials designed to confirm this benefit are nearing completion. PCSK9 inhibitors have been shown to reduce LDL-C levels safely and effectively in statin-intolerant patients. ${ }^{34}$ Currently, PCSK9 inhibitors are approved for patients with familial hypercholesterolemia or clinical atherosclerotic CVD who require additional LDL-C-lowering and are recommended for these indications in current guidelines. $9,10,30$ However, they are reported to not be costeffective for either of these conditions because of their high cost. $^{35}$

\section{Success of Guidelines}

The implementation of guidelines improves patient outcomes. ${ }^{36}$ However, physician adherence and patient compliance with guidelines is generally thought to be suboptimal, and undertreatment is common in high-risk groups, particularly among disadvantaged populations. For example, in a study across 22 countries in 2016, 66\% of individuals aged 35-70 years with CVD were using statin therapy in high-income countries such as Sweden or Canada, but only $27 \%$ in upper middle-income countries such as Poland, Turkey, or Brazil, and approximately 5\% in lowerincome countries such as China or India. ${ }^{37}$ Interventions to improve physician adherence have a modest effect, at least in the short-term. ${ }^{38}$ The incidence of atherosclerotic CVD has decreased over the past 2 decades in Western Europe, ${ }^{39}$ the United States, ${ }^{40}$ and Canada. ${ }^{41}$ The contribution of CV guidelines to this improvement is open to debate. In any case, it is reasonable to expect that better guidelines adherence by physicians, as well as better patient compliance, will lead to better outcomes for patients at risk for $\mathrm{CV}$ events.

"The people heard it, and approved the doctrine, and immediately practiced the contrary."

-Benjamin Franklin, The Way to Wealth

\section{Disclosures}

The authors have no conflicts of interest to disclose.

\section{References}

1. US Department of Health and Human Services. Agency for Healthcare Research and Quality. National Guideline Clearinghouse. Available at: www.guideline.gov. Accessed April 28, 2016.

2. Tricoci P, Allen JM, Kramer JM, Califf RM, Smith SC. Scientific evidence underlying the ACC/AHA clinical practice guidelines. JAMA 2009;301:831-41.

3. Institute of Medicine In: Graham R, Mancher M, Wolman DM, Greenfield S, Steinberg E, eds. Clinical Practice Guidelines We Can Trust. Washington, DC: National Academies Press, 2011.

4. Nix MP. What a difference a year makes: 1 year after implementing the AHRQ National Guideline Clearinghouse's revised inclusion criteria. Available at: http://growthevidence.com/what-a-difference-a-year-makes-1year-after-implementing-the-ahrq-national-guideline-clearinghousesrevised-inclusion-criteria/. Accessed April 28, 2016.

5. Mora S. Nonfasting for routine lipid testing. From evidence to action. JAMA Intern Med 2016;176:1005-6.

6. Reiner Z, Catapano AL, De Backer G, et al. ESC/EAS guidelines for the management of dyslipidaemias: the task force for the management of dyslipidaemias of the European Society of Cardiology (ESC) and the European Atherosclerosis Society (EAS). Eur Heart J 2011;32:1769-818.

7. NICE. National Institute for Health and Care and Excellence. Lipid modification: cardiovascular risk assessment and the modification of blood lipids for the primary and secondary prevention of cardiovascular disease. Available at: https://www.nice.org.uk/guidance/cg181. Accessed April 30, 2016.

8. Stone NJ, Robinson JG, Lichtenstein AH, et al. 2013 ACC/AHA guideline on the treatment of blood cholesterol to reduce atherosclerotic cardiovascular risk in adults: a report of the American College of Cardiology/American Heart Association Task Force on Practice Guidelines. Circulation 2014;129(suppl 2):S1-45.

9. Anderson TJ, Grégoire J, Pearson GJ, et al. 2016 Canadian Cardiovascular Society guidelines for the management of dyslipidemia for the 
prevention of cardiovascular disease in the adult. Can J Cardiol 2016;32: 1263-82.

10. Catapano AL, Graham I, De Backer G, et al. 2016 ESC/EAS Guidelines for the Management of Dyslipidaemias: the Task Force for the Management of Dyslipidaemias of the European Society of Cardiology (ESC) and European Atherosclerosis Society (EAS) developed with the special contribution of the European Association for Cardiovascular Prevention \& Rehabilitation (EACPR). Eur Heart J 2016;37:2999-3058.

11. Verbeek R, Hovingh GK, Boekholdt SM. Non-high-density lipoprotein cholesterol: current status as cardiovascular marker. Curr Opin Lipidol 2015;26:502-10.

12. Wilson PW, D'Agostino RB, Levy D, et al. Prediction of coronary heart disease using risk factor categories. Circulation 1998;97:1837-47.

13. D’Agostino RB Sr, Vassan RS, Pencina MJ, et al. General cardiovascular risk profile for use in primary care: the Framingham Heart Study. Circulation 2008;117:743-53.

14. Eichler K, Puhan MA, Steurer J, Bachmann LM. Prediction of first coronary events with the Framingham score: a systematic review. Am Heart J 2007;153:722-31.

15. Sivapalaratnam S, Boekholdt SM, Trip MD, et al. Family history of premature coronary heart disease and risk prediction in the EPICNorfolk prospective population study. Heart 2010;96:1985-9.

16. Goff DC, Lloyd-Jones DM, Bennett G, et al. 2013 ACC/AHA guideline on the assessment of cardiovascular risk. A report of the American College of Cardiology/American Heart Association task force on practice guidelines. Circulation 2014;129(25 suppl 2):S49-73.

17. Hippisley-Cox J, Coupland C, Vinogradova Y, et al. Predicting cardiovascular risk in England and Wales: prospective derivation and validation of QRISK2. BMJ 2008;336:1475-82.

18. Ference BA, Yoo W, Alesh I, et al. Effect of long-term exposure to lower low-density lipoprotein cholesterol beginning early in life on the risk of coronary heart disease. A Mendelian randomization analysis. J Am Coll Cardiol 2012;60:631-9.

19. Khera AV, Won HH, Peloso GM, et al. Diagnostic yield and clinical utility of sequencing familial hypercholesterolemia genes in patients with severe hypercholesterolemia. J Am Coll Cardiol 2016;67:2578-89.

20. Cholesterol Treatment Trialists' (CTT) Collaboration. Efficacy and safety of more intensive lowering of LDL cholesterol: a meta-analysis of data from 170,000 participants in 26 randomised trials. Lancet 2010;376:1670-81.

21. Bangalore S, Fayyad R, Kastelein JJ, et al. 2013 Cholesterol guidelines revisited: percent LDL cholesterol reduction or attained LDL cholesterol level or both for prognosis? Am J Med 2016;129:384-91.

22. Robinson JG, Ray K. Counterpoint: low-density lipoprotein cholesterol targets are not needed in lipid treatment guidelines. Arterioscler Thromb Vasc Biol 2016;36:586-90.

23. Writing committee, Lloyd-Jones DM, Morris PB, et al. 2016 ACC expert consensus decision pathway on the role of non-statin therapies for LDL-cholesterol lowering in the management of atherosclerotic cardiovascular disease risk: a report of the American College of Cardiology Task Force on Clinical Expert Consensus Documents. J Am Coll Cardiol 2016;68:92-125.

24. Boekholdt SM, Hovingh GK, Mora S, et al. Very low levels of atherogenic lipoproteins and the risk for cardiovascular events: a meta-analysis of statin trials. J Am Coll Cardiol 2014;64:485-94.
25. Ridker PM, Mora S, Rose L. JUPITER Trial Study Group. Percent reduction in LDL cholesterol following high-intensity statin therapy: potential implications for guidelines and for the prescription of emerging lipid-lowering agents. Eur Heart J 2016;37:1373-9.

26. Soran H, Schofield JD, Durrington PN. Cholesterol, not just cardiovascular risk, is important in deciding who should receive statin treatment. Eur Heart J 2015;36:2975-83.

27. Robinson JG. Lower might be better - it matters how you get there, and in whom. Eur Heart J 2016;37:1380-3.

28. Thanassoulis G, Williams K, Altobelli KK, et al. Individualized statin benefit for determining statin eligibility in the primary prevention of cardiovascular disease. Circulation 2016;133:1574-81.

29. Steel N. Thresholds for taking antihypertensive drugs in different professional and lay groups: questionnaire survey. BMJ 2000;320:1446-7.

30. Collins R, Reith C, Emberson J, et al. Interpretation of the evidence for the efficacy and safety of statin therapy. Lancet 2016;388:2532-61.

31. Cannon CP, Blazing MA, Giugliano RP, et al. Ezetimibe added to statin therapy after acute coronary syndromes. N Engl J Med 2015;372: 2387-97.

32. FDA Briefing Document. Endocrinologic and Metabolic Drugs Advisory Committee, December 14, 2015. Available at: http://www.fda.gov/ downloads/AdvisoryCommittees/CommitteesMeetingMaterials/Drugs/ EndocrinologicandMetabolicDrugsAdvisoryCommittee/UCM476505. pdf. Accessed December 10, 2016.

33. Waters DD, Hsue PY. PCSK9 inhibitors to lower LDL-cholesterol and reduce cardiovascular risk. Great expectations. Circ Res 2015;116: $1643-5$.

34. Waters DD, Hsue PY, Bangalore S. PCSK9 inhibitors for statin intolerance? JAMA 2016;315:1571-2.

35. Kazi DS, Moran AE, Coxson PG, et al. Cost-effectiveness of PCSK9 inhibitor therapy in patients with heterozygous familial hypercholesterolemia or atherosclerotic cardiovascular disease. JAMA 2016;316:743-53.

36. Grimshaw JM, Russell IT. Effect of clinical guidelines on medical practice: a systematic review of rigorous evaluations. Lancet 1993;342: 1317-22.

37. Yusuf S, Islam S, Chow CK, et al. Use of secondary prevention drugs for cardiovascular disease in the community in high-income, middle-income, and low-income countries (the PURE Study): a prospective epidemiological survey. Lancet 2011;378:1231-43.

38. Jeffery RA, To MJ, Hayduk-Costa G, et al. Interventions to improve adherence to cardiovascular disease guidelines: a systematic review. BMC Fam Pract 2015;16:147.

39. Nichols M, Townsend N, Scarborough P, Rayner M. Cardiovascular disease in Europe 2014: epidemiological update. Eur Heart J 2014;35: 2950-9.

40. Sidney S, Quesenberry CP Jr, Jaffe MG, et al. Recent trends in cardiovascular mortality in the United States and public health goals. JAMA Cardiol 2016;1:594-9.

41. Tu JV, Khan AM, Ng K, Chu A. Temporal changes in atherosclerotic cardiovascular diseases in Ontario, Canada, 1994 to 2014. Can J Cardiol, in press. 